\title{
Continuing the Validation of CCIM Processability for Glass Ceramic HLLW Forms: Plan for Test AFY14CCIM-GC1 FCRD-SWF-2014-000443
}

Vince Maio

April 2014

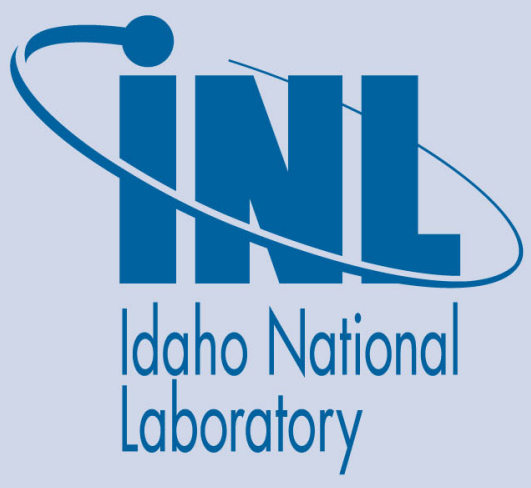

The INL is a U.S. Department of Energy National Laboratory operated by Battelle Energy Alliance 


\section{DISCLAIMER}

This information was prepared as an account of work sponsored by an agency of the U.S. Government. Neither the U.S. Government nor any agency thereof, nor any of their employees, makes any warranty, expressed or implied, or assumes any legal liability or responsibility for the accuracy, completeness, or usefulness, of any information, apparatus, product, or process disclosed, or represents that its use would not infringe privately owned rights. References herein to any specific commercial product, process, or service by trade name, trade mark, manufacturer, or otherwise, does not necessarily constitute or imply its endorsement, recommendation, or favoring by the U.S. Government or any agency thereof. The views and opinions of authors expressed herein do not necessarily state or reflect those of the U.S. Government or any agency thereof. 

INL/EXT-13-28250

Revision 0

\title{
Continuing the Validation of CCIM Processability for Glass Ceramic HLLW Forms: Plan for Test AFY14CCIM-GC1 FCRD-SWF-2014-000443
}

\author{
Vince Maio
}

April 2014

\section{Idaho National Laboratory \\ DOE-NE/Fuel Cycle Research and Development \\ Separations and Waste Forms}

Project 1.02.03.08 FT-14IN030807-Cold Crucible Induction Melter Test with Glass-

Ceramic Waste Forms-INL

Milestone Level 4M4FT-14IN0308073 “Complete and Formally Issue a Run Plan for AFY14CCIM-GC1"

Idaho Falls, Idaho 83415

http://www.inl.gov

Prepared for the

U.S. Department of Energy

Office of Nuclear Energy

Under DOE Idaho Operations Office

Contract DE-AC07-05ID145 



\begin{abstract}
This test plan covers test AFY14CCIM-GC1which is the first of two scheduled FY-2014 test runs involving glass ceramic waste forms in the Idaho National Laboratory's Cold Crucible Induction Melter Pilot Plant. The test plan is based on the successes and challenges of previous tests performed in FY-2012 and FY-2013. The purpose of this test is to continue to collect data for validating the glass ceramic High Level Liquid Waste form processability advantages using Cold Crucible Induction Melter technology. The major objective of AFYCCIM-GC1 is to complete additional proposed crucible pouring and post tapping controlled cooling experiments not completed during previous tests due to crucible drain failure. This is necessary to qualify that no heat treatments in standard waste disposal canisters are necessary for the operational scale production of glass ceramic waste forms. Other objectives include the production and post-test analysis of surrogate waste forms made from separate pours into the same graphite mold canister, testing the robustness of an upgraded crucible bottom drain and drain heater assembly, testing the effectiveness of inductive melt initiation using a resistive starter ring with a square wave configuration, and observing the tapped molten flow behavior in pans with areas identical to standard High Level Waste disposal canisters. Testing conditions, the surrogate waste composition, key testing steps, testing parameters, and sampling and analysis requirements are defined.
\end{abstract}




\section{CONTENTS}

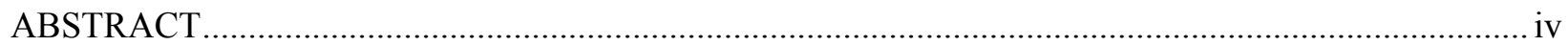

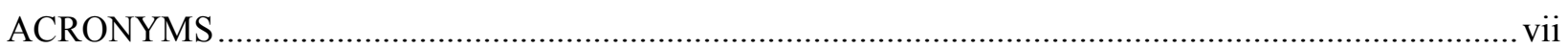

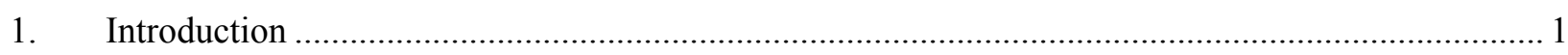

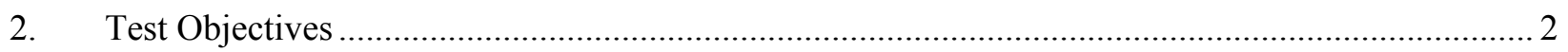

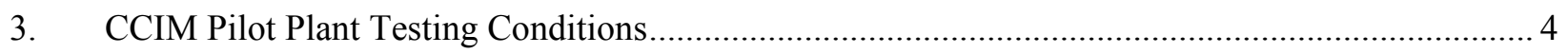

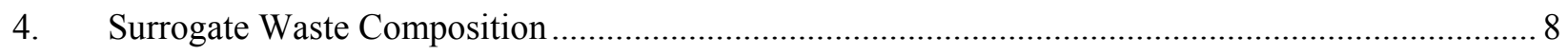

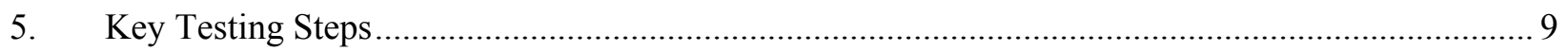

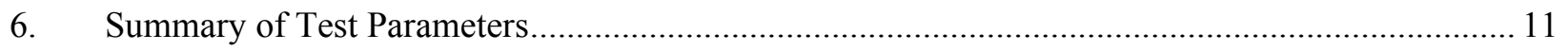

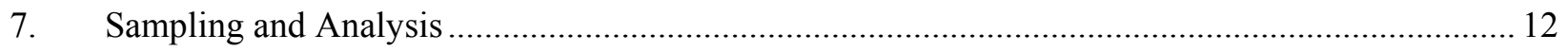

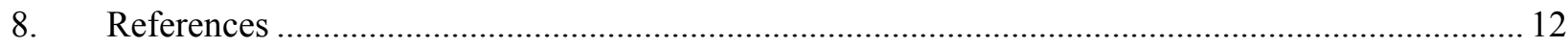

\section{FIGURES}

Figure 1 Schematic cut away view of the CCIM. Compared to a JHM, the lack of in-melt electrodes and refractory in a CCIM allow for greater mixing, longer life, greater

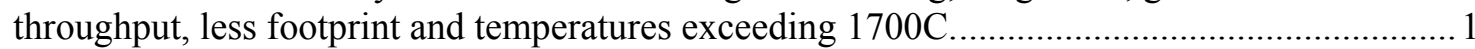

Figure 2 The $26.1 \mathrm{~cm}$ diameter, 6 turn (induction coil) crucible of the INL's CCIM Pilot Plant

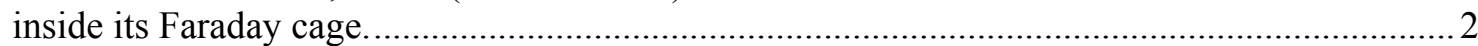

Figure 3 Centerline natural cooling curves for standard canisters at the baseline slowest case and two and three times faster than the slowest case

Figure 4 The controlled cooling system in its rolling cart in place beneath the crucible and Faraday cage Graphite molds are contained in the three heating mantles.

Figure 5 Centerline cooling rates of melt in graphite molds to set controller parameters to emulate Figure 3 cooling rates at 2 to 3 times faster than the slowest standard canister rate

Figure 6 Observed damage to the bottom drain sheath top (in the crucible melt) and drain clamshell heater. The latter when exposed for over an hour at high temperatures/amperages as needed to melt solid crystals in the drain tube.

Figure 7 Tube shell heater with potted coils around a Hastelloy drain tube with a wider 1/2 diameter

Figure 8 The specified compressed 6 turn CCIM single induction coil on the left compared to the previously used un compressed 6 turn coil on the right. The previous coil used a 3-3-3 coil design to allow switching of a 6 turn coil between upper and lower parts of the crucible

Figure 9 INL CCIM Pilot Plant feed system on the mezzanine level. (A) shows the liquid/sludge mixing tank with a barrel of simulated waste. (B) shows the solids feed hopper connected directly to the crucible below 


\section{TABLES}

Table 1 Unsalted HLLW surrogate solid oxide/frit mix composition for test AFY14CCIM-GC1 ............. 8

Table 2 Target operating parameters for test AFY14CCIM-GC1 …..................................................... 11 


\section{ACRONYMS}

$\operatorname{ccc}$

CCIM

CS

DOE-NE

FCRD

FPs

HLLW

INL

JHM

LN

PNNL

RF

SEM

TC

TM

TRL

XRD
Canister Centerline Cooling

Cold Crucible Induction Melter

Alkali and Alkaline Earth Fission Products (Cesium and Strontium)

Department of Energy Office of Nuclear Energy

Fuel Cycle Research and Development

Fission Products

High Level Liquid Waste (Liquid Raffinate)

Idaho National Laboratory

Joule Heated Melter

Lanthanide Fission Products

Pacific Northwest National Laboratory

Radio Frequency

Scanning Electron Microscopy

Thermocouple

Transition Metal Fission Products

Technical Readiness Level

X-ray Diffraction 


\section{Continuing the Validation of CCIM Processability for Glass Ceramic HLLW Forms: Plan for Test AFY14CCIM-GC1}

\section{Introduction}

Compared to High Level Liquid Waste (HLLW) glass disposal forms, glass ceramic forms offer significant advantages in terms of higher HLLW loadings, longer radionuclide retention, increased radiation and radiation heat tolerance, and increased durability. Additionally, Cold Crucible Induction Melting (CCIM) technology, in contrast to the established Joule Heated Melter (JHM), better accommodates the formation of glass ceramic forms given the CCIM's higher temperatures, efficient mixing, tolerance to crystal (i.e., ceramic mineral) formation and bottom drain configuration. See Figure 1. This CCIM/glass ceramic waste form combination may be well suited for the HLLW raffinates produced from advanced fuel cycle technologies under development by the Department of Energy's (DOE's) Fuel Cycle Research and Development Program (FCRD).

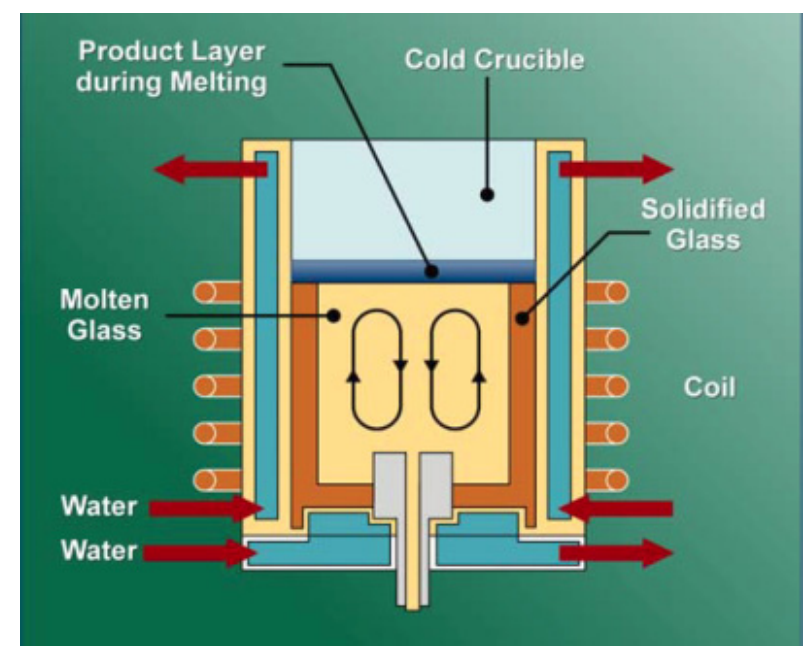

Figure 1 Schematic cut away view of the CCIM. Compared to a JHM, the lack of in-melt electrodes and refractory in a CCIM allow for greater mixing, longer life, greater throughput, less footprint and temperatures exceeding $1700^{\circ} \mathrm{C}$.

To validate the above premise, FY 2012 tests in INL's CCIM Pilot Plant, as shown in Figure 2 , successfully immobilized surrogate HLLW raffinates into durable glass ceramic waste forms. The tests produced glass ceramic waste form surrogates with a $150 \%$ increase in waste loading compared to that achievable with the same surrogate in standard borosilicate glass (BSG). These results indicate the inherent benefits of a CCIM favor the production of glass ceramic waste forms (references 1-5). However, the FY 2012 tests as well as attempted FY-2013 tests pointed toward areas for continued development to ensure the CCIM and its ability to produce glass ceramic waste forms is further validated to move the CCIM to a technology readiness level (TRL) for operational use in radioactive environments. 


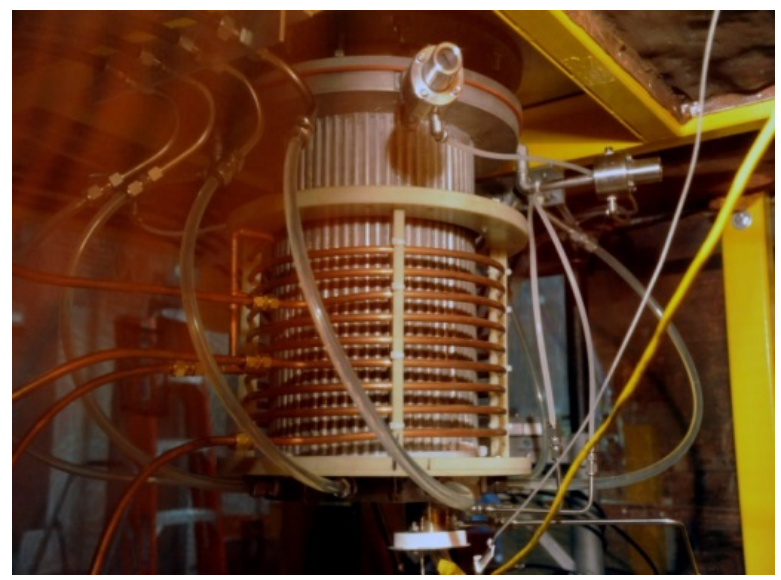

Figure 2 The $26.1 \mathrm{~cm}$ diameter, 6 turn (induction coil) crucible of the INL's CCIM Pilot Plant inside its Faraday cage.

This test plan outlines the objectives, operating conditions, HLLW surrogate composition, key test steps, test parameters, and post-test waste form sampling and analysis for the first of two FY 2014 INL CCIM Pilot Plant tests involving glass ceramic surrogate waste forms and is designated test AFY14CCIM-GC1. The goal of this test is to continue the glass ceramic processability validation associated with the advantageous features inherent with the CCIM technology and is a continuation of the successful tests completed in FY 2012 and the attempted test in FY 2013. Related to this goal is the need to demonstrate reliable draining and post drain waste form curing (as required for glass ceramics at pilot scale) over a range of three waste form cooling profiles.

\section{Test Objectives}

The overall objective will be to convert, upon melting, the amorphous/crystalline surrogate HLLW in the CCIM into a durable HLLW form with high waste loadings by taking advantage of the precious metals (e.g., ruthenium, rhodium, palladium and silver) in the HLLW and the controlled cooled graphite molds to form particular crystals dispersed in a glass phase. The precious metals created as fission products serve as seeding points for crystal formation and it is the specific crystalline ceramics that provide for the high waste loadings and greater durability compared to BSG.

Specific objectives include:

1. Completion of taps and pours to finalize the boundary on cooling rates for the post tapped waste forms. For these tests, a scaled 4" diameter graphite mold with a programmable heater is used to simulate the cooling rate of the full size 2 foot diameter waste canisters. The desire is to be able to use natural cooling of the canisters and the objective of this testing is to better define the limiting cooling rate that still produces the desired ceramics. FY 2012 tests on 4" samples indicated that acceptable glass ceramics are formed at the slowest theoretical natural cooling rate representative of a standard $2 \mathrm{ft}$. diameter canister. Natural cooling of 4" samples resulted in undesirable ceramic formation. Based on these results, test AFY14CCIM-GC1 will conduct controlled cooling in the graphite molds at 2, 3 and 4 times faster than the slowest natural cooling rate of a standard canister. Cooling rates two and three times faster than the slowest standard canister natural cooling rate are 
shown in the graph of Figure 3. As in previous tests, the pours are to occur in 4" diameter graphite molds (equipped with radial and axial thermocouple trees) surrounded by heating mantles on a custom designed rolling cart below the crucible. See Figure 4. Due to latency, the set point temperature for the mantles is to be taken from the mantles' thermocouples (TC) as opposed to the TCs in the molten pours.

To ensure accuracy in matching these center line rates, the heating mantle temperature controller's parameters were preset by melting (and then cooling) solid ground waste forms from a previous melt. Curves for these parameter setting tests are provided in Figure 5 for comparison to Figure 3, and attempts to make them more accurate will continue up to test time. If appropriate waste forms are formed at the faster cooling rates, this will demonstrate that heat treatment of the waste form in a standard canister located in a "hot" cell is not required. This is a successful result for cost and efficiency for glass ceramic HLLW form production in an operational scale CCIM.

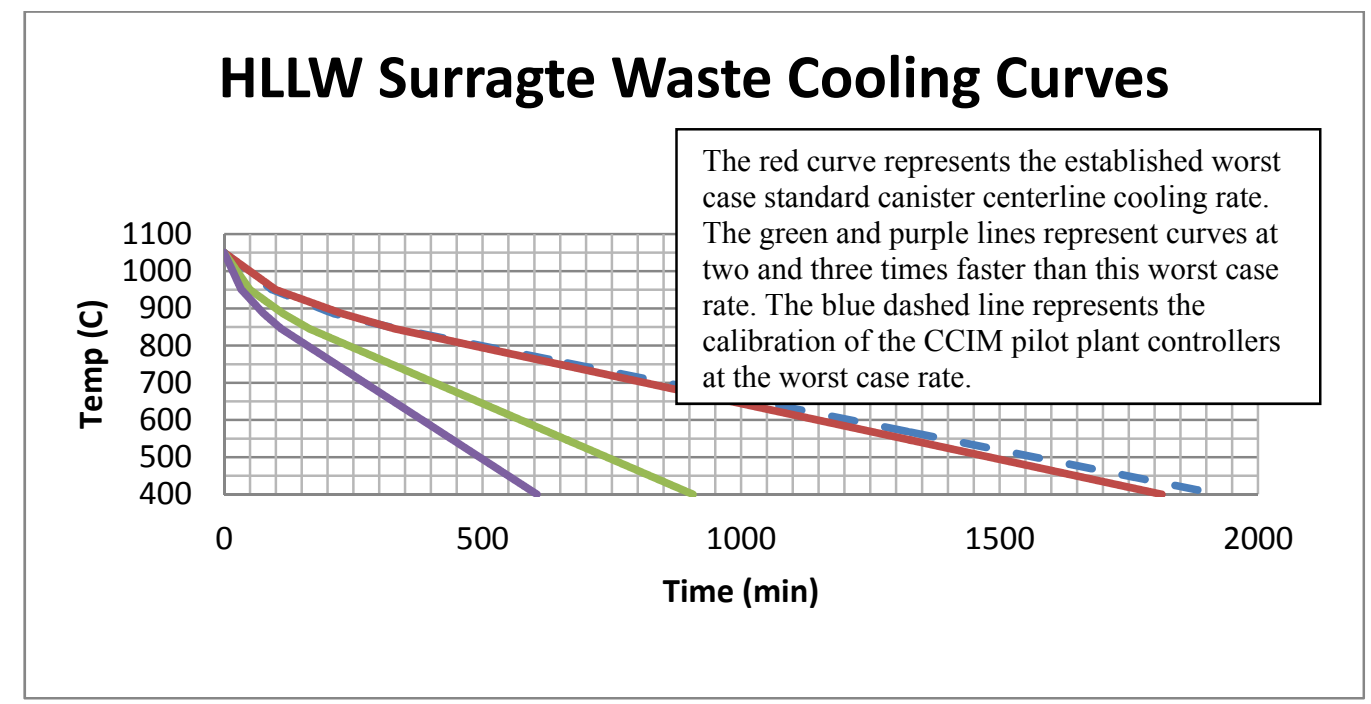

Figure 3 Center line natural cooling curves for standard canisters at the baseline slowest case and two and three times faster than the slowest case

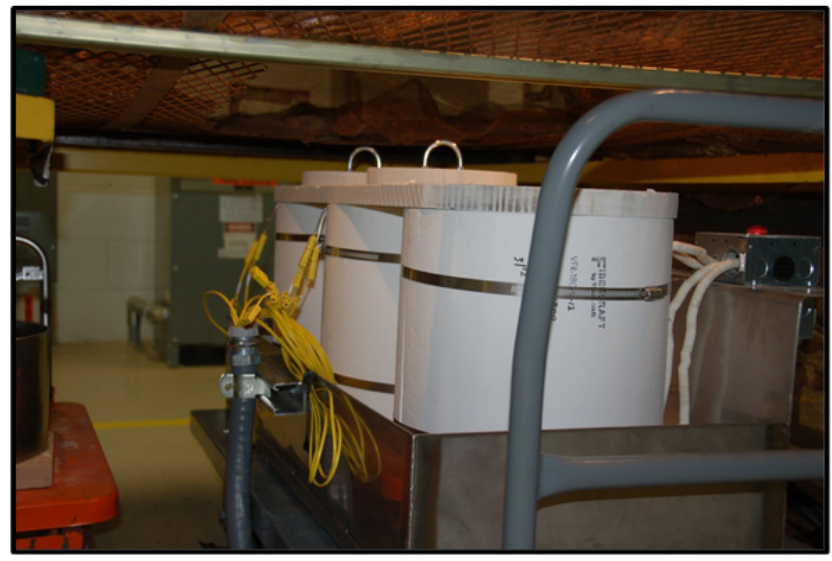

Figure 4 The controlled cooling system in its rolling cart in place beneath the crucible and Faraday cage; graphite molds are contained in the three heating mantles. 


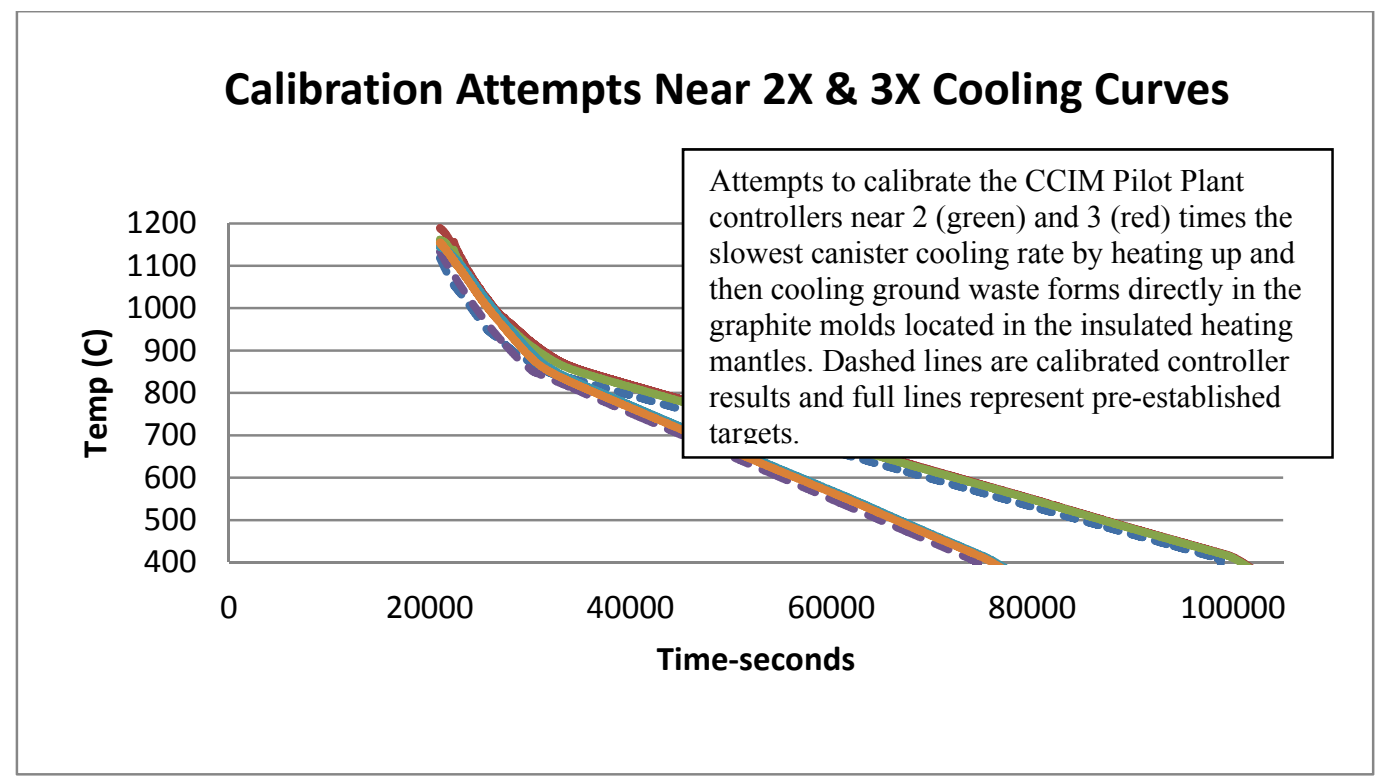

Figure 1 Center-line cooling rates of melt in graphite molds to set controller parameters to emulate Figure 3 cooling rates at 2 to 3 times faster than the slowest standard canister rate

2. Completion of crucible taps and pours to determine the effects of multiple pours (pours on top of pours in the same mold) on the formation of the glass ceramic under a no reset cooling rate condition. This type of pour is necessary to reflect natural conditions of canister filling for operations on a production scale. The new pour will reheat the earlier pour which is under control cooling to emulate a natural centerline cooling of a $2 \mathrm{ft}$. standard canister. Post analysis of the completely cooled form will reveal the effects of this pouring on the waste's form's overall composition. It is important that the right crystals are still formed and the right waste species migrate to their appropriate crystal to ensure that the benefits of high overall canister waste loading and waste form durability are achievable under actual canister filling conditions. The second pour is to occur no sooner than three hours after the first pour.

3. Observe the behavior of the molten glass ceramic waste form when it is poured into a pan with a standard disposal canister diameter. This test is important to visually observe if the molten waste can completely fill or nearly completely fill the total cross section of a standard canister diameter. There is value in assessing the cooling rate of the glass ceramic as it flows to the outer edges of the canister to ensure there are no voids in filling

\section{CCIM Pilot Plant Testing Conditions}

INL's CCIM's Pilot Plant and RF generator were designed in 2002 for DOE legacy defense waste, such as those existing in Hanford's underground storage tanks. Its design-basis frequency for operation was established at $2.0 \mathrm{MHz}$ to align with the legacy waste's conductivity of $20 \mathrm{~S} / \mathrm{M}$ (or mhos); which has a corresponding resistivity of $5 \mathrm{ohm}-\mathrm{cm}$. The conductivity of the surrogate HLLW and the glass-ceramic waste tested in FY-2012 was substantially lower; it had an average low conductivity of $10 \mathrm{~S} / \mathrm{m}$; corresponding to a resistivity of $10 \mathrm{ohm}-\mathrm{cm}$. This value is twice the value of legacy waste and higher than any other waste the CCIM Pilot Plant and its RF generator had attempted to couple to and melt in the past. After two unsuccessful trials to ignite the 
surrogate solid oxide HLLW, a successful coupling was achieved with a thick titanium ring as an initiator as opposed to a previously used wire. To support and assist the induction ignition of this resistive bed, conductive sodium carbonate was added in and around the titanium ring initiator on top of the bed and to a lesser extent throughout the bed.

These changes enabled a time efficient melt ignition and subsequent molten bed tapping to achieve three pours of glass ceramics that were cooled at three different rate profiles. However, high power levels were required to maintain the melt in FY 2012, leading to inefficiencies in energy use and near automatic shutdown of the RF generator. In addition more planned pours were not achieved as a result of repeated drain heater failure and drain material corrosion. In an attempt to remedy the challenges of coupling/power inefficiencies and drain/drain heater failure, FY 2013 funding was received and solutions were designed, implemented and, where possible, tested (Reference 6).

The high power requirement for the RF generator was due to a mismatch between the resistivity of the waste form material and design frequency of the RF generator. The resistivity of the material to be melted, the frequency of the induced current and the diameter of the crucible must all be considered in a manner to efficiently deliver energy to the waste form material. In this case the design frequency (i.e., 2.0 MHz) was not high enough (e.g., 4-6 MHz) to maintain the resistive melt at $\sim 1300^{\circ} \mathrm{C}$ unless high power levels were maintained. This condition was unacceptable for sustained CCIM Pilot Plant operation.

The approach used to raise the frequency range of the RF generator to facilitate efficient coupling of the more resistant melt involved lowering the capacitance with the removal of an existing fixed capacitor and installation of a variable capacitor in the capacitance bank located between the RF generator chassis and the crucible. Since this change in capacitance controls the L-C circuit behavior characteristic of RF induction melters ( as long as there are no changes in crucible diameter and inductance), calculations and follow on testing validated that frequencies of over $4 \mathrm{MHz}$ were obtainable upon the completion of tuning experiments with the new capacitor. Even though this frequency was closer to optimum for the resistive melt, attempts to initiate and sustain the melt at higher frequency levels led to considerable interference of many instruments throughout the CCIM Pilot Plant; several of them critical for safe operation. Despite costly efforts to eliminate the interference (e.g., remounting and re wiring of instrument panels, removal of over 100 yards of unconnected and abandoned instrument wire in the overhead trays, etc.) the interference was not fully reduced to a safe level. As such this test run will be operated near the design frequency (1.8 to $2.2 \mathrm{MHz}$ ) and operating time with be minimized to avoid the risk of the RF generator automatically shutting down due it's high power interlocks. Operating on the design frequency for test AFY14 CCIM-GCI will require replacing the new variable capacitor with the older design basis fixed capacitor and "salting" the solid surrogate bed with sodium carbonate

The drain heater failure and excessive drain material corrosion were due to the high melting point and crystalline nature of the waste form. See figure 6 . The formulation being tested had a melting point of approximately $1350^{\circ} \mathrm{C}$ which is higher than the $1050^{\circ} \mathrm{C}$ melting point of most glass formulations. In addition, crystalline materials are true solids and therefore go through a phase transition; this requires an extended heating time to deliver the heat required for the phase transition. Pure glasses only require softening. 


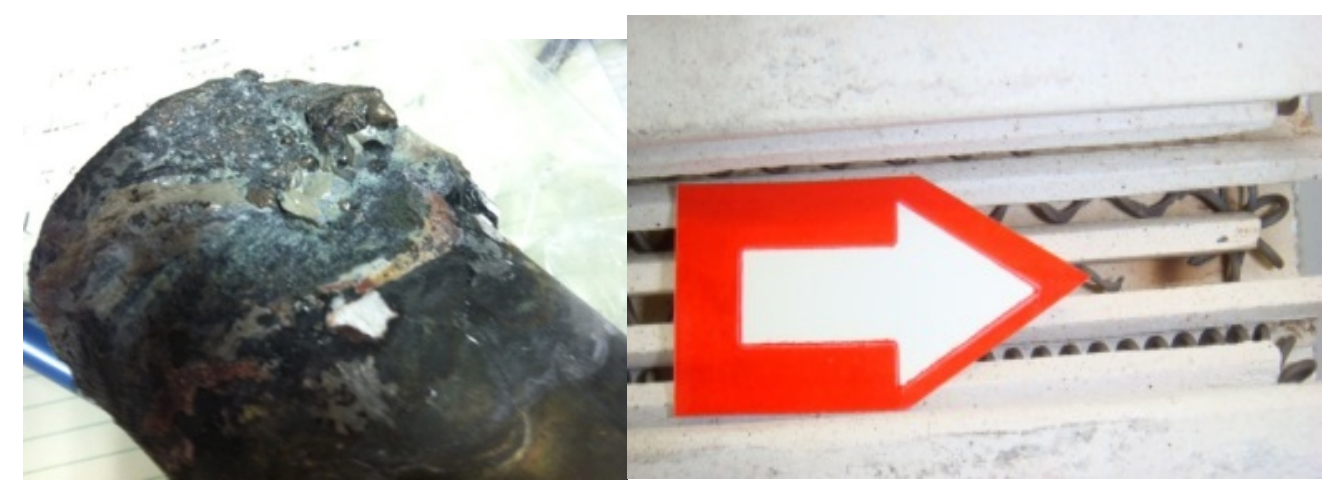

Figure 6 Observed damage to the bottom drain sheath top (in the crucible melt) and drain clamshell heater. The latter when exposed for over an hour at high temperatures/amperages as needed to melt solid crystals in the drain tube.

The most immediate and least costly fix for the crucible drain assembly and its heater was to keep their same configurations; but implement the following modifications:

- Potting of the open area around the resistive heater's coiled wire elements. See Figure 7. This may keep the elements from sagging and snapping after exposure to cycling and high amperage (i.e., high temperatures) for long time periods ( $>30 \mathrm{~min}$.). As note earlier the higher temperatures over longer periods are necessary to melt crystals remaining in the drain tube after the previous tapping and subsequent pouring. In contrast, glass does not require latent heat input over a long duration, since it's amorphous behavior requires less energy (for shorter time periods) for the sensible heat needed to simply increase the glass's temperature and decrease it's viscosity (1-6 Pa-sec) for easier pouring. The potted heaters were tested over several slow heating cycles $\left(100-1000^{\circ} \mathrm{C}\right)$ to verify their robustness and to precondition their resistive wire elements for both cycling and thermal shock.

- Increasing the pour tube diameter from $3 / 8$ to $1 / 2$ inch

- Replacing the existing exhaust blower with one of greater vacuum and less flow to ensure drain pour control

- Addition of a nitrogen purge to the top end of the drain assembly's sheath exposed to the $1300^{\circ} \mathrm{C}$ plus molten environment in the crucible.

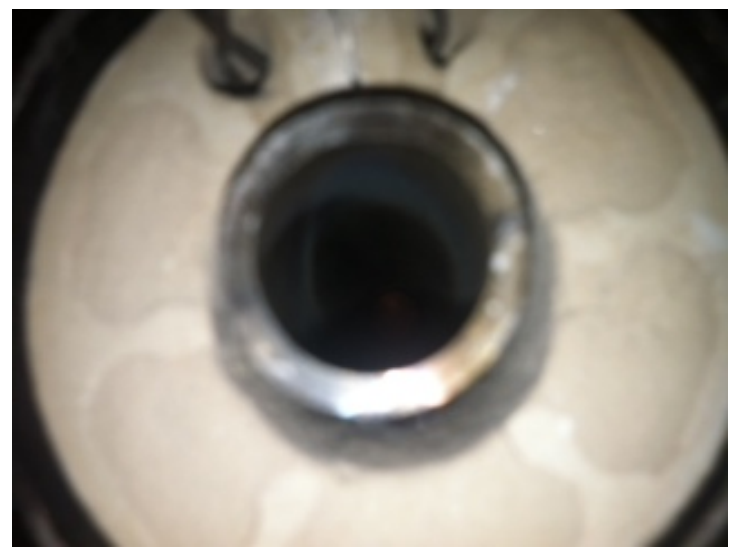

Figure 7 Tube shell heater with potted coils around a Hastelloy drain tube with a wider 1/2 diameter 
Other operating changes pertinent to this test are a result of the surrogate HLLW solid oxide frit mixture not obtaining melt initiation. Partial ignition of the surrogate was only achieved once, despite the FY-2013 attempts to salt the bed, locate and remove non-desired induction sources and try a variety of initiator rings and wires of various shapes. Unlike the surrogate feed made in 2012, which was melted from base oxides to an amorphous mix by MOSCI Corporation of Rolla Missouri, the surrogate used in the test attempted in FY-2013 and to be used for test AFY14CCIM-GC1 was formulated by low temperature melting (1.e., 900-1000 ${ }^{\circ} \mathrm{C}$ ) of left over FY 2012 liquid surrogate HLLW prepared by NAOH Corporation of San Antonio. Specifically, 80 gallons of liquid HLLW surrogate containing glass frit was converted to $\sim 53 \mathrm{kgs}$ of solid ground oxides consisting of an amorphous and crystalline ceramic mix; with about $40 \%$ being ceramic. Compared to the FY 2012 surrogate composition, the surrogate for this test has a higher ceramic content and requires an initiation temperature in excess of $1300^{\circ} \mathrm{C}$. This higher temperature revealed itself during FY 2013 testing when several initiators of increasing resistance were tried with little success over a range of tuning frequencies. To ensure ignition of the surrogate solid oxide HLLW/frit for test AFY14CCIM-GC1, it will be reground to about 0.8 $\mathrm{mm}$ or less and an induction ring of high resistance (i.e., titanium) in a square wave pattern will be used. This special pattern will maximize heat generation and distribution in the optimum torus region of the crucible's cross section.

FY2013 testing revealed that when long induction ring ignition times are required as a result of high ceramic content in the surrogate, RF generator power cannot couple fast enough to the surrogate; eventually electrically stressing components in the generator's chassis. As before this is a consequence of the induction ring not conducting enough heat to support the latent heat to melt the ceramic phase. The inability to obtain "load" in less than an hour for the RF generator's power led to burnout of two switches (the existing switch and its replacement) that control use of the lower or upper induction coils surrounding the crucible. This switch will not be replaced for test AFY14CCIM-GC1 and a single 6 turn induction coil will be utilized for surrogate bed initiation and melting. This coil will be compressed to provide for an increase in power density of $\sim 40 \%$ to the surrogate bed as shown in Figure 8 . This increase in power density will alleviate challenges related to the surrogate's ceramic content and its high resistivity.
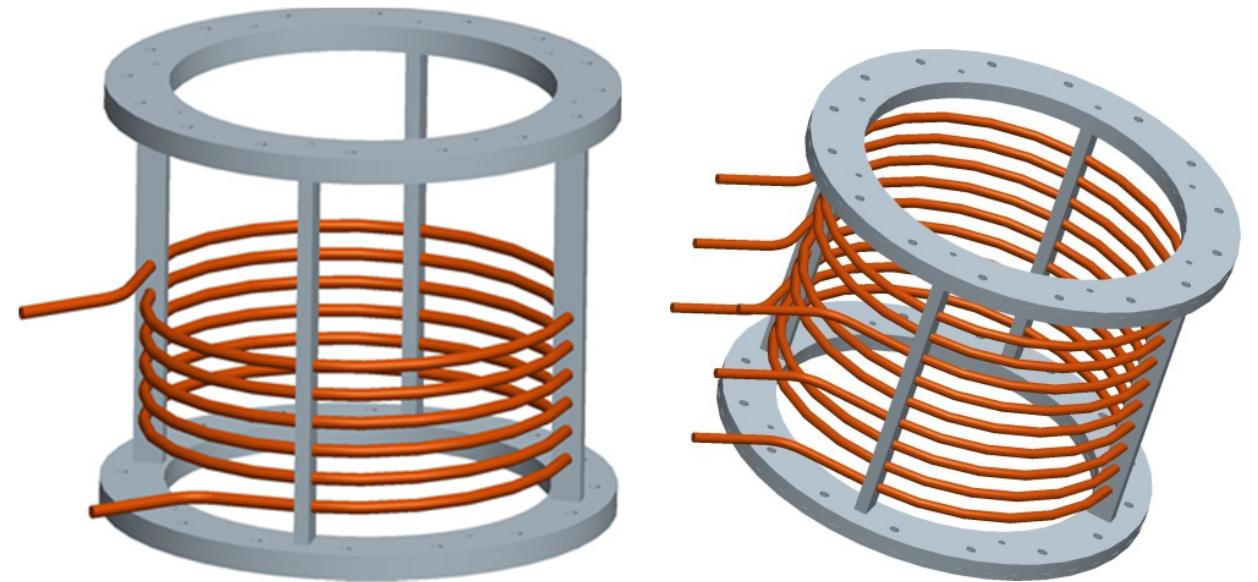

Figure 8 The specified compressed 6 turn CCIM single induction coil on the left compared to the previously used un compressed 6 turn coil on the right. The previous coil used a 3-3-3 coil design to allow switching of a 6 turn coil between upper and lower parts of the crucible 


\section{Surrogate Waste Composition}

Like the FY 2012 test, the non-radioactive surrogate for this test (which is the same dry oxide surrogate used for the attempted FY 2013 test) was prepared to contain the of nonradioactive oxide components representative of the fission products expected in HLLW from future SNF recycling. In general it is the combination of projected separate raffinate streams produced separately during and advanced SNF aqueous separation process

The surrogate contains representatives of the alkaline and alkaline earth fission products; mainly cesium and strontium, the lanthanide fission products and the transition metal fission products; and has the designation of CS/LN/TM-6.25Mo. The latter part of the designation indicates the HLLW surrogate contains quantities of molybdenum to mirror the high concentration of this particular fission product (and fission product daughter) expected in commercial SNF. The surrogate also contains the correct amount of oxide frits required to produce the desired glass ceramic formations as determined by PNNL in FY 2010 and 2011(References 7 and 8).This MOSCI formulated surrogate bed was also doped with lithium carbonate by NAOH to account for the bed's low conductivity. Its composition based on PNNL recipes provided to MOSCI and NOAH is presented in Table 1. Note that the first five highlighted constituents in the table are the glass forming 'frit' compounds. The remaining constitute the HLLW surrogate in oxide form.

Table 1 Unsalted HLLW surrogate solid oxide/frit mix composition for test AFY14CCIM-GC1

\begin{tabular}{|l|c|}
\hline $\begin{array}{c}\text { HLLW Surrogate Solid } \\
\text { Oxide/Frit Mix } \\
\text { CS/LN/TM Mo-6,25 }\end{array}$ & $\begin{array}{c}\text { Targeted Composition } \\
\text { wt.\% }\end{array}$ \\
\hline $\mathrm{Al}_{2} \mathrm{O}_{3}$ & $5.00 \%$ \\
\hline $\mathrm{B}_{2} \mathrm{O}_{3}$ & $9.40 \%$ \\
\hline $\mathrm{CaO}$ & $4.26 \%$ \\
\hline $\mathrm{Na}_{2} \mathrm{O}$ & $3.54 \%$ \\
\hline $\mathrm{SiO}_{2}$ & $32.82 \%$ \\
\hline $\mathrm{MoO}$ & $6.25 \%$ \\
\hline $\mathrm{SrO}$ & $1.57 \%$ \\
\hline $\mathrm{BaO}$ & $3.53 \%$ \\
\hline $\mathrm{Rb} \mathrm{O}_{2} \mathrm{O}$ & $0.68 \%$ \\
\hline $\mathrm{Cs}_{2} \mathrm{O}$ & $4.60 \%$ \\
\hline $\mathrm{Y}_{2} \mathrm{O}_{3}$ & $1.00 \%$ \\
\hline $\mathrm{Ce}_{2} \mathrm{O}_{3}$ & $4.96 \%$ \\
\hline $\mathrm{Eu}_{2} \mathrm{O}_{3}$ & $0.27 \%$ \\
\hline $\mathrm{G}_{2} \mathrm{O}_{3}$ & $0.26 \%$ \\
\hline $\mathrm{La}_{2} \mathrm{O}_{3}$ & $2.53 \%$ \\
\hline $\mathrm{Nd}_{2} \mathrm{O}_{3}$ & $8.38 \%$ \\
\hline $\mathrm{Pr}_{2} \mathrm{O}_{3}$ & $2.32 \%$ \\
\hline $\mathrm{Sm}_{2} \mathrm{O}_{3}$ & $1.72 \%$ \\
\hline $\mathrm{ZrO}_{2}$ & $4.77 \%$ \\
\hline $\mathrm{RuO}_{2}$ & $0.10 \%$ \\
\hline $\mathrm{Ag}_{2} \mathrm{O}$ & $0.18 \%$ \\
\hline $\mathrm{SnO}_{2}$ & $0.11 \%$ \\
\hline $\mathrm{TeO}_{2}$ & $1.05 \%$ \\
\hline $\mathrm{Waste}_{2}$ loading & $\mathbf{4 4 . 5 9 \%}$ \\
\hline
\end{tabular}




\section{Key Testing Steps}

Based on the discussion above, the following steps are listed below to meet the particular AFY14CCIM-GC1 test objectives. The Operating Manuals of references 9 and 10 are to be used for all CCIM Pilot Plant operational steps.

1. After pre-coating and drying the crucible (with the appropriate installed drain assembly as noted in Section 3) as well as installing the compressed induction coil assembly, load the crucible (using respirators and the fume trunk) with $\sim 15$ to $20 \mathrm{kgs}$ of pre-salted, pre-weighed and pre ground surrogate HLLW/ frit mix and place the pre-fabricated titanium square wave induction wire on the surface of the bed. This will position the induction ring approximately $1 / 4$ down the granulated bed's top surface when the entire surrogate is loaded in the crucible. "Salt" the region around the ring with sodium carbonate to assist in bed initiating and coupling. Salting amounts for both the area around the induction ring and throughout the surrogate will be calculated before the test and recorded in the CCIM Pilot Plant's operational log book.

2. As per the Operating Manuals of reference, pre-start the RF generator and cooling systems for both the generator and crucible.

3. Increase the power of the RF generator to the crucible's L-C circuit by bringing power levels up accordingly per the Operating Manuals and tune, via the vacuum tubes, the generator's frequency to match and maximize heating of the titanium induction ring with the new square wave configuration.

4. As observable via the view ports and cameras, conductive heat transfer will, within 40 minutes, elevate the temperature of the surrogate dry solid waste in an annular region surrounding the titanium ring. When a molten mass occurs attempt to successfully couple to the molten region by dialing into the optimum frequency of the $\mathrm{RF}$ generator. When coupling is successful and generator load is obtained, besides notable changes in both grid and plate current, heat losses as a result of conduction and convection (which are proportional to the crucible's cross-sectional surface area) will be overcome by the growing melt region as the melt incorporates more and more of the un-melted HLLW/frit mix.

5. Stabilize all RF generator and cooling system parameters to maintain (for at least an hour) a molten temperature in the crucible in the range of $1300^{\circ} \mathrm{C}$ to $1400^{\circ} \mathrm{C}$ as measured by the appropriate thermocouple (TC) readings. Record data as appropriate and document through both written and instrument validation the achievement of a maximum temperature of $1350^{\circ} \mathrm{C}$ or above and the total time that temperature is maintained. The reaching of this temperature for sufficient time will ensure all the crystals are fully molten.

6. To meet the objectives, prepare to begin crucible tapping and draining operations via operation of the drain heater's rheostat and monitoring of its TC.

7. The first tap and pour is to be done in a 4" diameter graphite mold at a centerline canister cooling rate $(\mathrm{ccc})$ representative of twice the rate of the worst case slowest rate for a standard $2 \mathrm{ft}$. canister. This pour is to last long enough to fill at least 6" of the graphite mold's height. Time from start of tap to stopping of the pour is to be 
recorded to determine mass flow rates at a later time. Pyrometer readings of the pour are to be taken at least twice during the pour and the temperatures recorded.

8. The second tap is to be done in a 4" diameter graphite mold at a ccc rate representative of three times the rate of the worst case slowest rate for a standard $2 \mathrm{ft}$. canister. This pour is to last long enough to fill at least 6" of the graphite molds height. Time from start of tap to stopping of the pour is to be recorded to determine mass flow rates at a later time. Pyrometer readings of the pour are to be taken at least twice during the pour and the temperatures recorded.

9. The third tap is to be done in a 4-inch graphite mold at a ccc rate representative of four times the rate of the worst case slowest cooling rate for a standard $2 \mathrm{ft}$. canister. This pour is to last long enough to fill approximately 4" of the graphite molds height (the shorter fill depth is to allow room for an additional pour, per step 11). Time from start of tap to stopping of the pour is to be recorded to determine mass flow rates at a later time. Pyrometer readings of the pour are to be taken at least twice during the pour and the temperatures recorded.

10. At this point slowly gravity deposit into the crucible the balance of the remaining HLLW dry surrogate oxide/frit mix that has been previously placed in the hopper on the mezzanine level of the CCIM Pilot Plant. See Figure 9. Feed the surrogate /frit mix in slowly to avoid cooling and solidifying the existing molten glass which could cause the induction power to lose coupling to the melt, After a full molten bed is established melt for an additional hour at $1350^{\circ} \mathrm{C}$ or greater.

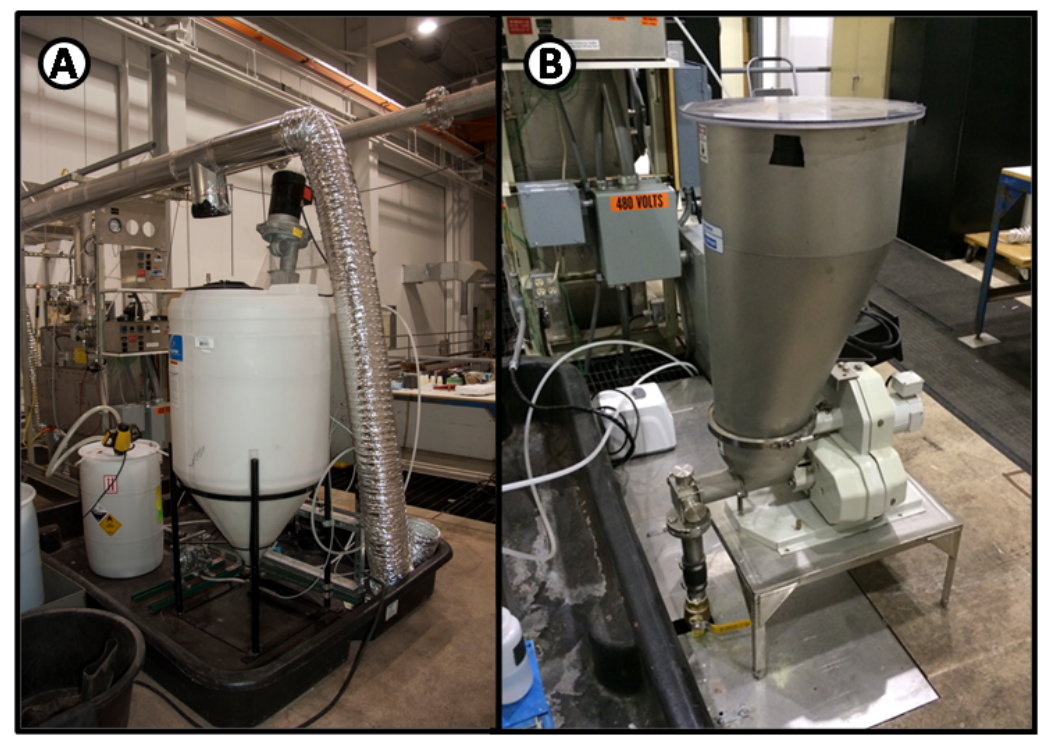

Figure 9 INL CCIM Pilot Plant feed system on the mezzanine level. (A) shows the liquid/sludge mixing tank with a barrel of simulated waste. (B) shows the solids feed hopper connected directly to the crucible below

11. The fourth tap is to be placed on the cooling molten pour established in step 9 for the purpose of identifying how this pouring situation, which will occur for operational scale canister fillings, effects the waste form's morphology in terms of crystal 
formation and surrogate fission product distribution in the final waste form. This pour is to last long enough to fill up to at least 8 " of the graphite mold's height. Time form start of tap to stopping of the pour is to be recorded to determine mass flow rates at a later time. Pyrometer readings of the pour are to be taken at least twice during the pour and the temperatures recorded. For this pour on pour case, the controlled cooling is not to be reset from its initiation time in step 9 .

12. The last pour is to "dump" the remaining crucible molten bed into a 6" high stainless steel pan $2 \mathrm{ft}$. in diameter (US standard canister size) or into a 6" high stainless steel pan $1.4 \mathrm{ft}$. diameter (European standard canister size). The purpose of this pour is to qualitatively determine the flow characteristics of a glass ceramic in standard canisters. Examples to be noted through observation include if the glass ceramic cools before filling the entire base area of the canister. As before with the graphite mold taps and pours, the time from start of tap to stopping of the pour in the pan is to be recorded to determine mass flow rates at a later time. Pyrometer readings of the pours are to be taken at least twice during the pour and the temperatures recorded. Since the existing melter of the CCIM Pilot Plant is estimated to be between a $1 / 4$ and $1 / 3$ of an operational scale facility, it's unlikely that its smaller drain size and corresponding volumetric pour rate is significant enough to achieve a valid experiment using the US or international standard canister diameters . The CCIM researchers are aware of this potential challenge and will likely be using the international standard diameter canister and observe the relative diameter of the pour. The CCIM Pilot Plant also has a 6" high stainless steel pan with a 1 foot diameter. Since this pan's area is $1 / 4$ of that of the US standard canister's area, a future pour experiment into this pan will provide a closer estimate of the CCIM Pilot Plant's scale relative to that of an actual production scale melter.

\section{Summary of Test Parameters}

Table 2 Target operating parameters for test AFY14CCIM-GC1

\begin{tabular}{|c|c|c|}
\hline Parameter & Units & Value/Description \\
\hline \multicolumn{3}{|l|}{ Melter Feed: } \\
\hline $\begin{array}{l}\text { Projected surrogate waste (HLLW) } \\
\text { loading on a mass basis in the final } \\
\text { glass-ceramic waste form }\end{array}$ & $\begin{array}{c}\text { mass } \\
\text { percent }\end{array}$ & $\sim 45 \%$ (expected) \\
\hline Melter feed rate & na & \\
\hline Duration & hrs. & $9-16$ \\
\hline \multicolumn{3}{|l|}{ Melter: } \\
\hline Induction power & $\mathrm{kW}$ & $\begin{array}{l}\text { Up to } 50 \text { should be sufficient enough for } \\
\text { maintaining the target glass temperature }\end{array}$ \\
\hline Desired induction frequency & $\mathrm{MHz}$ & $1.8-2.2$ \\
\hline $\begin{array}{l}\text { Estimated melt conductivity near } \\
\text { the melt temperature }\end{array}$ & $\begin{array}{l}\mathrm{S} / \mathrm{m} \\
\mathrm{mhos}\end{array}$ & $8-12$ \\
\hline $\begin{array}{l}\text { Melt viscosity range near melt } \\
\text { temperature }\end{array}$ & Pa-sec & $1-6$ \\
\hline $\begin{array}{l}\text { Desired Melter Temperature } \\
\text { Range }\end{array}$ & ${ }^{\circ} \mathrm{C}$ & $1300-1400$ \\
\hline
\end{tabular}




\section{Scope of sampling/ measurements:}

Fully cooled product ( waste

form) with glass ceramics in all

three molds
SEMS, XRD, and EDS after shipping to

PNNL

\section{Sampling and Analysis}

Once the three tapped and poured melts are controlled cooled to room temperature, each of the three graphite mold cylinders will be shipped to PNNL. There they will be cored both vertically and radially to measure the degree of space and temperature homogeneity, and then analyzed for the following:

- X-Ray Diffraction (XRD) - for phase identification only (i.e., glass versus ceramic phases)

- Energy Dispersive Spectroscopy (EDS) - for quantitative phase analysis. This analysis provides the amount of each phase and classifies the crystalline phases

- Scanning Electron Microscopy (SEM) micrographs/elemental spot analysis - along with EDS, provides component distribution in the various phases for single components.

X-ray tomography will be attempted to 3-diamensionally locate the various dispersed crystal and continuous glass phases throughout the controlled cooled waste form after it is removed from the graphite mold canister. Samples will be taken from the canister for analysis by optical microscopy, SEM, and X-ray powder diffraction as noted above. These samples will be obtained by core drilling horizontally through the top, middle, and bottom regions of the cylindrical waste form. Cross-sections of the core sample will then be made at each end and in the middle of the waste form. The polished cross-sections will be examined under the optical microscope at magnifications up to of $1000 \mathrm{X}$. A core drill will also be made vertically through the canister and cross-sectioned near the top, middle and bottom of the waste form.

\section{References}

1. Maio, V.C. (2011). "Idaho National Laboratory Cold Crucible Induction Melter (CCIM) Test With a Glass-Ceramic Waste Form -FT121N030801," INL/MIS-11-23916, Idaho National Laboratory, November 9. 2011.

2. Maio, V.C. (2012). "Validation of the Completion of a CCIM Test Run to Produce a Glass Ceramic Waste Form,” INL/MIS-12-26813, Idaho National Laboratory, July 31, 2012

3. Maio, V.C. (2012). "Advanced Waste Forms and Processes-FCRD-SWF Idaho National Laboratory Cold Crucible Induction Melter (CCIM) Test With a Glass-Ceramic Waste Form -FT121N030801," Presentation at U.S. Department of Energy, Office of Nuclear Energy, August 14-16- 2012.

4. Maio, V.C. (2012). "The Use of Cold Crucible Induction Melters for Effectively Producing Advanced Glass -Ceramic Radioactive HLW Forms," INL/CON-12-27410, 
Presentation at the Materials Science and Technology 2012 Conference and Exhibition, Pittsburg, PA, October 8-12.

5. Rutledge, V. J., and V. C. Maio (2013) "The Production of Advanced Glass-Ceramic HLW Forms using Cold Crucible Induction Melters," Presentation at Global 2013 International Nuclear Fuel Cycle Conference, Salt Lake City, UT, September 29 October 3, 2013.

6. Maio, V.C. (2013). “CCIM FCRD SWF 2013 Mid-Year Review,” INL/MIS-13-28816, Revision 1, Idaho National Laboratory, April 9. 2013.

7. Riley, B.J., et.al, Initial Laboratory-Scale Melter Test Results for Combined Fission Product Waste, AFCI-WAST-PMOMI-DV-2009-000184, 2009

8. Crum, J.V., et.al., Glass Ceramic Waste Forms for Combined CS+LN+TM Fission Products Waste Streams, FCRD-WAST-2010-000181, 2010

9. INL/MIS-14-1238, INL Cold Crucible Induction Melter Radio Frequency Generator Operations Manual

10. INL/MIS-14-1239 INL Cold Crucible Induction Melter Balance of Plant Operations Manual 